\title{
Sensitivity of Heat of Reaction for Polyurethane Foams
}

\author{
DENNIS PAU ${ }^{1}$, CHARLES FLEISCHMANN ${ }^{1}$, MICHAEL SPEARPOINT $^{1}$, and KAI-YUAN LI ${ }^{2}$ \\ ${ }^{1}$ Department of Civil and Natural Resources Engineering, \\ University of Canterbury, \\ Christchurch 8140, \\ New Zealand \\ 2 State Key Lab of Fire Science, \\ University of Science and Technology of China, \\ Hefei 230027, \\ China
}

\begin{abstract}
The heat of reaction for the decomposition of polyurethane foam and its melt are determined from the heat flow measurements obtained through simultaneous differential scanning calorimetry and thermogravimetric analysis. Under nitrogen environment, the decomposition of foam experiences two endothermic pyrolysis reactions based on the experimental results. Through the investigation on the sensitivity of heat of reaction to heating rate and sample mass, a region where the heat of reaction remains constant is found for the melt samples tested. This consistent region includes heating rate from 5 to $20^{\circ} \mathrm{C} / \mathrm{min}$ and sample mass between $\sim 20$ and $\sim 50 \mathrm{mg}$. No consistent region is found for the foam samples because of the reduced accuracy in the heat flow measured. For the foams and melts tested, the consistent heat of reaction for the second reaction ranges from endothermic $164-295 \mathrm{~J} / \mathrm{g}$ while the recommended heat of reaction for the first reaction ranges from endothermic $610-1023 \mathrm{~J} / \mathrm{g}$.
\end{abstract}

KEYWORDS: fire chemistry, heat of reaction, polyurethane foam, differential scanning calorimetry.

\section{INTRODUCTION}

Rein et al. [1] modelled the decomposition and smouldering behaviours of polyurethane foam. Subsequently, Valencia [2] investigated the type of products released during foam decomposition. These studies [1] and [2] have shown the decomposition of polyurethane foam in a nitrogen environment proceeds via two pyrolysis reactions listed as followed. The decomposition products identified by Valencia [2] are included in brackets.

First Reaction:

Second Reaction:

$$
\begin{aligned}
& \text { Polyurethane foam } \rightarrow \text { Melt (Polyol) }+ \text { Gas (Isocyanate) } \\
& \text { Melt (Polyol) } \rightarrow \text { Char }+ \text { Gas (Polyol, } \mathrm{H}_{2} \mathrm{CO}, \mathrm{H}_{2} \mathrm{O} \text { and } \mathrm{CH}_{4} \text { ) }
\end{aligned}
$$

When the polyurethane foam reaches the decomposition temperature, it decomposes into melt and gas through the first reaction. From typical results of thermogravimetric analysis experiments in nitrogen [3], by the end of the first reaction, the remaining melt is approximately $75 \%$ of the original sample mass. When the temperature increases further, the melt decomposes almost entirely into gas through the second reaction, leaving behind small amount of char residue.

During the smouldering phase of a fire or before piloted ignition, polyurethane foam exposed to heat will be oxidised to some degree by the oxygen in the air. However, oxidation is seldom included in the description of foam decomposition under sustainable flaming because after ignition, any available oxygen is assumed to be consumed within the flame before reaching the fuel bed to cause oxidation [4]. Therefore, the two pyrolysis reactions listed above remain as a simplified mean of describing the combustion of polyurethane foam.

From fundamental thermochemistry, in order for a reaction such as the decomposition of material to initiate or to progress further, an amount of energy is absorbed or released by the material [5]. The reactions absorbing energy are endothermic in nature while those releasing energy are exothermic. The amount of energy that changes is termed the heat of reaction and this is a user defined input in many combustion models available such as Fire Dynamics Simulator, Version 5 [6] (FDS 5) and Gpyro [7]. The objective of this paper is to experimentally determine the heats of reaction for the two decomposition reactions of 
polyurethane foams in nitrogen which can then be used as inputs into FDS 5 to simulate the burning behaviours.

The experimental technique applied is known as simultaneous differential scanning calorimetry and thermogravimetric analysis (SDT). The differential scanning calorimetry (DSC) measures the heat flow of a reaction while the thermogravimetric analysis (TGA) measures the sample mass of a reaction. From the changes in heat flow and sample mass, the heat of reaction is determined. The terminology of the heat of reaction adopted in this paper is the same as the terminology adopted in FDS 5 which is the change in the amount of energy per unit mass of reactant converting into products. A number of studies discussed as followed have used DSC and TGA experiments to determine the heat of reaction during the decomposition of materials. Some of the heats of reaction reported in the literature have been calculated based on the original sample mass rather than the amount of reactant converted into products. So in accordance with the definition adopted in this paper, some of these literature values presented have been recalculated.

The study of Rath et al. [8] involved the decomposition of wood in nitrogen and two wood species, spruce and beech were investigated. The authors also studied the effect of using non-hermetic lid, different sample mass and different purge flow rates have on the heat of reaction. The use of non-hermetic lid, high sample mass and low purge flow rates were found to result in heat flow which is more exothermic in nature. Among the experimental variables studied, the use of lid produces the most significant changes in the heat of reaction. For spruce, the values without lid ranged from endothermic $300-472 \mathrm{~J} / \mathrm{g}$ while the values with lid ranged from endothermic $56-209 \mathrm{~J} / \mathrm{g}$. For beech, the values without lid ranged from endothermic $177-$ $180 \mathrm{~J} / \mathrm{g}$ while the values with lid ranged from exothermic $111-207 \mathrm{~J} / \mathrm{g}$.

Valencia [9] investigated the decomposition of polyurethane foam under nitrogen and the resulting heat flow was endothermic. The heat of reaction for the first and second reactions was 1009 and $331 \mathrm{~J} / \mathrm{g}$ respectively. Stoliarov et al. [10] investigated the decomposition of numerous common plastics and engineering polymers in nitrogen. These include polymethylmethacrylate (PMMA), polyoxymethylene (POM), polyethylene (PE), polypropylene (PP), polystyrene (PS), polyamide 6,6 (PA 66), polyethylene terephthalate (PET), bisphenol A polycarbonate (PC), polyvinylidene fluoride (PVDF) and polyvinyl chloride (PVC). The heats of reaction, $\Delta h_{r}$ were found to be endothermic and are tabulated in Table 1 .

Table 1. Heat of reaction for materials tested in Stoliarov et al. [10].

\begin{tabular}{|c|c|c|c|c|c|c|c|c|c|c|}
\hline Sample & PMMA & POM & PE & PP & PS & PA 66 & PET & PC & PVDF & PVC \\
\hline$\Delta \boldsymbol{h}_{\boldsymbol{r}}(\mathbf{J} / \mathbf{g})$ & 870 & 2540 & 920 & 1310 & 1000 & 1390 & 1800 & 830 & 2120 & 710 \\
\hline
\end{tabular}

Matala et al. in references [11] and [12] investigated the decomposition in nitrogen of birch, oak, pine, PVC, PMMA, graphite and various wood components such as cellulose, lignin and xylan. The authors reported that endothermic heat flow was obtained during the decomposition and the heat of reaction for cellulose and birch was 482 and $230 \mathrm{~J} / \mathrm{g}$ respectively. Peterson et al. [13] investigated the decomposition of PMMA in nitrogen environment. The heat flow was endothermic and the heat of reaction derived was $1080 \mathrm{~J} / \mathrm{g}$. The reported value is higher compared to the value reported by Stoliarov et al. [10]. Some of the samples were also tested by the respective authors in air whereby the heat flow was exothermic due to the presence of additional oxidative reactions. The heats of reaction in air from the literature were not reported because the focus of this paper was on the decomposition in nitrogen only.

\section{POLYURETHANE FOAMS AND MELTS INVESTIGATED}

This study investigated three non-fire retardant (NFR) polyurethane foams, four fire retardant (FR) polyurethane foams and their melts in the SDT experiment. The melt samples were obtained from a series of foam melting experiments [3] performed over different imposed heat fluxes under ambient air. During the experiment, a vertically oriented foam sample was exposed to a constant heat flux and the melting behaviour was investigated. In the foam melting experiments, the melt droplets formed on the surface of the decomposing foam flowed downwards with gravity and were eventually collected. At the end of the experiment, the melt which remained in liquid form at ambient temperature was stored in a sealed container for later testing in the SDT. 
The foam melting experiments were carried out in both non-flaming (NF) and flaming (F) conditions. Under non-flaming condition, the exposed surface of the foam decomposes but does not burn throughout the experiment while under the flaming condition, the exposed surface was pilot ignited. The FR foams were tested under both conditions but the NFR foams were only able to be tested in flaming condition due to the experimental challenges in maintaining uniform exposed surface under non-flaming condition. The identification given to the foam and melt samples is based on the known combustion resistive nature of the foam, an internal code for the research, the foam density and the type of condition under which melts are obtained. Table 2 provides the identification, foam hardness, density and chemical formula of the samples.

Table 2. General description of polyurethane foams and their melts tested in Simultaneous DSC-TGA experiment.

\begin{tabular}{|c|c|c|c|c|}
\hline Identification & Foam Hardness $^{\mathrm{a}}(\mathbf{N})$ & $\begin{array}{c}\text { Sample } \\
\text { Type }\end{array}$ & $\begin{array}{l}\text { Density } \\
\left(\mathrm{kg} / \mathrm{m}^{3}\right)\end{array}$ & Chemical Formula \\
\hline \multirow{2}{*}{ NFR-SB-31 } & \multirow{2}{*}{130} & Foam & 31 & $\mathrm{C}_{1.00} \mathrm{H}_{1.77} \mathrm{O}_{0.31} \mathrm{~N}_{0.06}$ \\
\hline & & Melt (F) & 1019 & $\mathrm{C}_{1.00} \mathrm{H}_{1.98} \mathrm{O}_{0.35} \mathrm{~N}_{0.01}$ \\
\hline \multirow{2}{*}{ NFR-DG-42 } & \multirow{2}{*}{80} & Foam & 42 & $\mathrm{C}_{1.00} \mathrm{H}_{1.84} \mathrm{O}_{0.33} \mathrm{~N}_{0.05}$ \\
\hline & & Melt (F) & 1025 & $\mathrm{C}_{1.00} \mathrm{H}_{2.03} \mathrm{O}_{0.36} \mathrm{~N}_{0.01}$ \\
\hline \multirow{2}{*}{ NFR-C-19 } & \multirow{2}{*}{60} & Foam & 19 & $\mathrm{C}_{1.00} \mathrm{H}_{1.75} \mathrm{O}_{0.31} \mathrm{~N}_{0.07}$ \\
\hline & & Melt (F) & 1034 & $\mathrm{C}_{1.00} \mathrm{H}_{1.99} \mathrm{O}_{0.36} \mathrm{~N}_{0.01}$ \\
\hline \multirow{3}{*}{ FR-Y-36 } & \multirow{3}{*}{130} & Foam & 36 & $\mathrm{C}_{1.00} \mathrm{H}_{1.69} \mathrm{O}_{0.28} \mathrm{~N}_{0.17} \mathrm{Cl}_{0.003} \mathrm{P}_{0.0010}$ \\
\hline & & Melt (NF) ${ }^{b}$ & 1054 & $\mathrm{C}_{1.00} \mathrm{H}_{1.95} \mathrm{O}_{0.33} \mathrm{~N}_{0.05} \mathrm{Cl}_{0.001}$ \\
\hline & & $\operatorname{Melt}(F)^{b}$ & 1047 & $\mathrm{C}_{1.00} \mathrm{H}_{1.96} \mathrm{O}_{0.33} \mathrm{~N}_{0.05} \mathrm{Cl}_{0.001}$ \\
\hline \multirow{3}{*}{ FR-LG-38 } & \multirow{3}{*}{80} & Foam & 38 & $\mathrm{C}_{1.00} \mathrm{H}_{1.73} \mathrm{O}_{0.28} \mathrm{~N}_{0.16} \mathrm{Cl}_{0.003} \mathrm{P}_{0.0002}$ \\
\hline & & Melt (NF) ${ }^{b}$ & 1052 & $\mathrm{C}_{1.00} \mathrm{H}_{1.91} \mathrm{O}_{0.32} \mathrm{~N}_{0.07} \mathrm{Cl}_{0.001}$ \\
\hline & & $\operatorname{Melt}(\mathrm{F})^{\mathrm{b}}$ & 1051 & $\mathrm{C}_{1.00} \mathrm{H}_{1.89} \mathrm{O}_{0.31} \mathrm{~N}_{0.07} \mathrm{Cl}_{0.001}$ \\
\hline \multirow{3}{*}{ FR-W-50 } & \multirow{3}{*}{120} & Foam & 50 & $\mathrm{C}_{1.00} \mathrm{H}_{1.74} \mathrm{O}_{0.32} \mathrm{~N}_{0.07} \mathrm{Cl}_{0.002} \mathrm{P}_{0.0004}$ \\
\hline & & Melt (NF) ${ }^{b}$ & 1046 & $\mathrm{C}_{1.00} \mathrm{H}_{1.93} \mathrm{O}_{0.34} \mathrm{~N}_{0.02} \mathrm{Cl}_{0.002}$ \\
\hline & & Melt $(\mathrm{F})^{\mathrm{b}}$ & 1038 & $\mathrm{C}_{1.00} \mathrm{H}_{1.98} \mathrm{O}_{0.34} \mathrm{~N}_{0.02} \mathrm{Cl}_{0.001}$ \\
\hline \multirow{3}{*}{ FR-G-32 } & \multirow{3}{*}{140} & Foam & 32 & $\mathrm{C}_{1.00} \mathrm{H}_{1.76} \mathrm{O}_{0.32} \mathrm{~N}_{0.06} \mathrm{Cl}_{0.016} \mathrm{P}_{0.0050}$ \\
\hline & & Melt (NF) ${ }^{b}$ & 1035 & $\mathrm{C}_{1.00} \mathrm{H}_{1.97} \mathrm{O}_{0.35} \mathrm{~N}_{0.02} \mathrm{Cl}_{0.001}$ \\
\hline & & $\operatorname{Melt}(\mathrm{F})^{\mathrm{b}}$ & 1027 & $\mathrm{C}_{1.00} \mathrm{H}_{1.99} \mathrm{O}_{0.35} \mathrm{~N}_{0.01} \mathrm{Cl}_{0.002}$ \\
\hline
\end{tabular}

${ }^{\mathrm{a}}$ Hardness as reported in manufacturer specifications

${ }^{\mathrm{b}} \mathrm{Phosphorus}$ was not tested for in the samples

\section{SIMULTANEOUS DSC-TGA EXPERIMENTS}

A simultaneous DSC-TGA Q Series ${ }^{\mathrm{TM}}$ instrument, SDT 600 manufactured by TA Instruments is used to carry out the DSC experiments in this research and the equipment also simultaneously conducts the TGA experiments by recording the changes in sample mass. The simultaneous experiment takes place within a gas purged furnace where the cup containing the sample is placed on the platform of the sample beam while an empty cup is placed on the platform of the reference beam. The cup used is made from alumina and measures $90 \mu \mathrm{L}$. SDT 600 operates based on the heat flux concept where the heat flow, $d q / d t$ is determined from the thermal equivalent of Ohm's Law as seen in Eq. 1.

$$
\frac{d q}{d t}=\frac{\Delta T_{\text {sam-ref }}}{R_{t}} \cdot k_{f} \cdot k_{u}
$$

$\Delta T_{\text {sam-ref }}$ is the difference between the sample and reference temperatures measured by the individual thermocouple located underneath the platinum lined platform. $R_{t}, k_{f}$ and $k_{u}$ are respectively the thermal resistance, the factory set calibration value and the user set calibration value which are obtained through a series of calibrations. The sample mass is measured through the current signal required to correct a taut-band meter movement [14] caused by the changes in sample mass. The calibrations for the equipment 
are performed in the following sequence, mass calibration, temperature calibration, heat flow calibration and cell constant calibration [15]. The complete details on the calibration process are documented in the online help of the equipment and also summarised in [3]. When there are changes to the heating rate and purge gas, the calibrations are carried out at the specific heating rate and temperature range which are applicable to the intended experiments.

In this research, the foam samples tested range from 3 to $10 \mathrm{mg}$ while the melt samples range from 3 to 50 $\mathrm{mg}$. The mass of 10 and $50 \mathrm{mg}$ for foam and melt samples are the respective maximum limit for the current setup based on the capacity of the alumina cups used. The foam sample is prepared by shredding the polyurethane foam into fine fragments and then transferring these fragments into the cup. The melt sample is prepared by freezing the melt droplets with liquid nitrogen for easy transfer into the cup and then the sample is allowed to return to ambient temperature before the start of experiment. All experiments are carried out in dynamic mode where the prepared sample is heated at constant heating rate from the room temperature to the maximum temperature of $600{ }^{\circ} \mathrm{C}$. The selected heating rates are $1,5,20$ and $60{ }^{\circ} \mathrm{C} / \mathrm{min}$ which are chosen based on the temperature variation of polyurethane foam smouldering front, reportedly varies between 1 and $150{ }^{\circ} \mathrm{C} / \mathrm{min}$ [1]. The chosen rates are also below the maximum allowable limit of $100{ }^{\circ} \mathrm{C} / \mathrm{min}$ for the equipment. The purge flow rate is $100 \mathrm{ml} / \mathrm{min}$ and nitrogen is used as purge gas which creates a non-reactive environment where the decomposition occurs under the sole influence of heat. As discussed earlier, the decomposition under nitrogen environment is theoretically similar to the decomposition of foam during flaming combustion where oxygen is consumed before reaching the pyrolysis front [4]. The sample is tested in open configuration without the presence of lid so the volatiles produced from decomposition can escape without being obstructed.

\section{DATA REDUCTION TO DETERMINE HEAT OF REACTION}

The decomposition of melt is the second reaction of the overall decomposition of polyurethane foam. The heat of reaction for melt decomposition is introduced first because the results are simpler and the data reduction process is much more straightforward compared to that of polyurethane foam decomposition which is discussed later. The results of $26 \mathrm{mg}$ NFR-SB-31 (F) melt at $5{ }^{\circ} \mathrm{C} / \mathrm{min}$ in Fig. 1 is used as an example to illustrate the data reduction process. Fig. 1 shows the TGA mass $l o s s /{ }^{\circ} \mathrm{C}$ and the DSC reaction heat flow plotted against the sample temperature. The melt decomposition is depicted by the single protuberance in the mass $\operatorname{loss} /{ }^{\circ} \mathrm{C}$ curve. This is in accordance with the pyrolysis mechanism of polyurethane foam proposed earlier where the melt only undergoes a single reaction to decompose completely into gas.

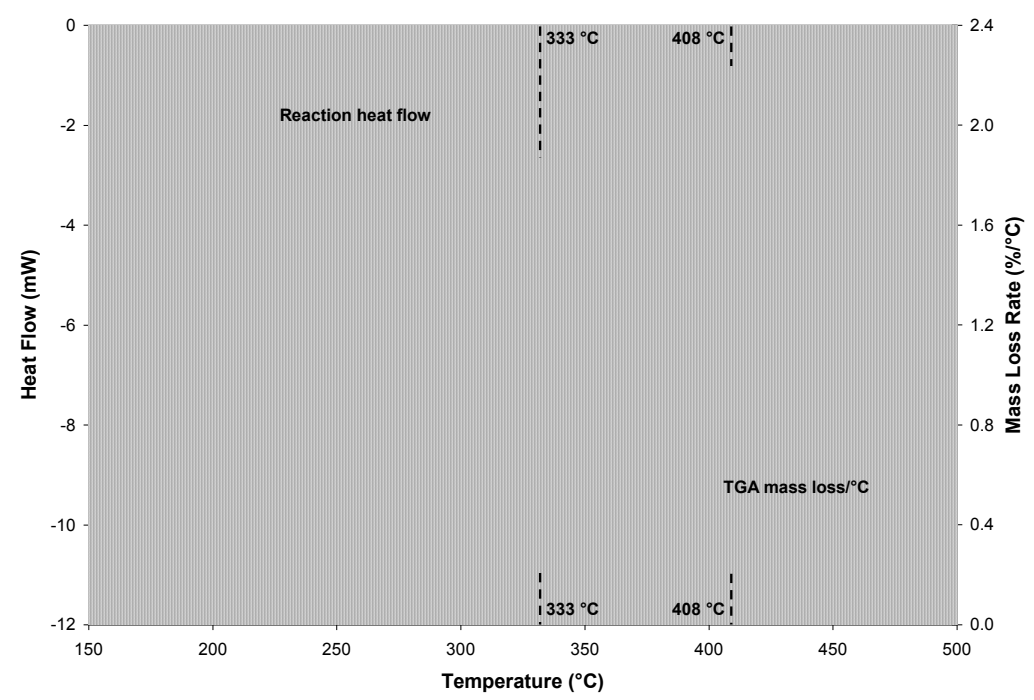

Fig. 1. TGA mass loss $/{ }^{\circ} \mathrm{C}$ and DSC reaction heat flow for $26 \mathrm{mg}$ NFR-SB-31 (F) melt at $5{ }^{\circ} \mathrm{C} / \mathrm{min}$ under nitrogen environment. 
Over the identical temperature range of the protuberance, the reaction heat flow curve shows an endothermic region indicated by the negative heat flow measured. Equation 2 is used to calculate the heat of reaction, $\Delta h_{r}$.

$$
\Delta h_{r}=\frac{1}{m_{\text {start }}-m_{\text {end }}} \int_{T_{\text {start }}}^{T_{\text {end }}}\left(\frac{d q}{d t}\right)_{R} d T \cdot \frac{d t}{d T}
$$

The numerator of Eq. 2 contains the temperature integral of the reaction heat flow, $(d q / d t)_{R}$ between two selected temperatures, $T_{\text {start }}$ and $T_{\text {end }}$ which are 333 and $408{ }^{\circ} \mathrm{C}$ as indicated in Fig. 1. The selected temperatures are where the TGA mass $l o s s /{ }^{\circ} \mathrm{C}$ is $10 \%$ of the difference between the maximum and minimum values of the specific reaction. The resulting integral is in unit of $\mathrm{mW}^{\circ} \mathrm{C}$. The amount of energy involved with the reaction is determined by dividing this integral with the heating rate used as the temperature increase within the experiment is governed by the constant heating rate applied. The denominator of Eq. 2 consists of the amount of sample mass consumed between $T_{\text {start }}$ and $T_{\text {end }}$. For NFR-SB-31 (F) at $5{ }^{\circ} \mathrm{C} / \mathrm{min}$, the heat of reaction for the melt decomposition is endothermic $231 \mathrm{~J} / \mathrm{g}$.

\section{HEAT OF REACTION FOR DECOMPOSITION OF MELTS (SECOND REACTION)}

The sensitivity of the heat of reaction towards the changes in heating rate and sample mass are investigated on two melts, NFR-SB-31 (F) and FR-Y-36 (F). Both melts are the respective decomposition product of non-fire retardant and fire retardant foams. The results of NFR-SB-31 (F) melts are used to illustrate the sensitivity towards the heating rate and sample mass. Fig. 2 shows the mass 10 ss $/{ }^{\circ} \mathrm{C}$, the reaction heat flow and the calculated heat of reaction for $\sim 20 \mathrm{mg}$ NFR-SB-31 (F) melts at heating rate of 1, 5, 20 and $60{ }^{\circ} \mathrm{C} / \mathrm{min}$. Again, the negative heat flow denotes endothermicity.

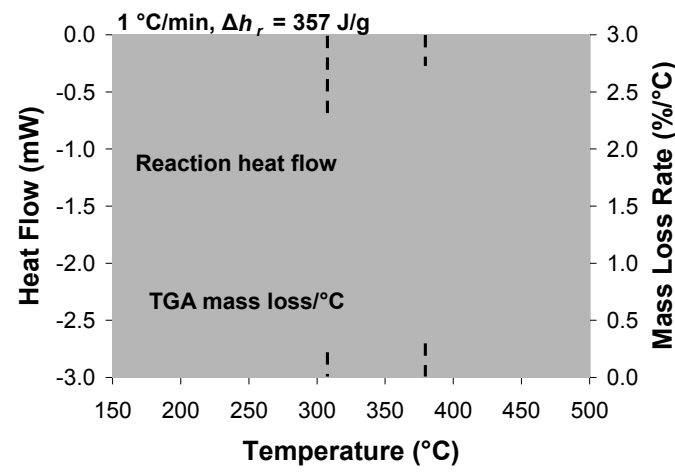

(a)

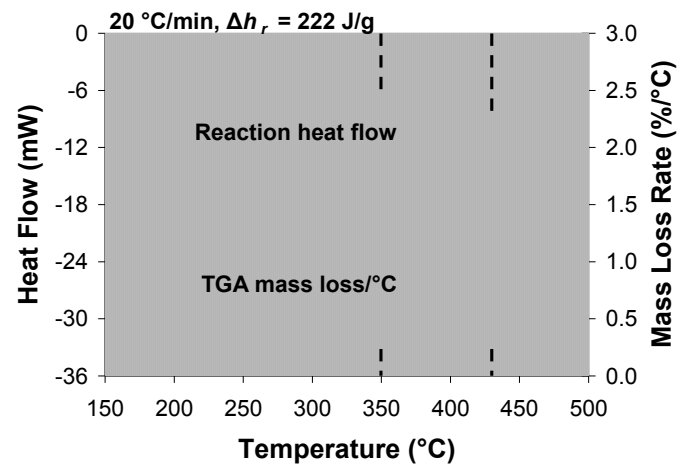

(c)

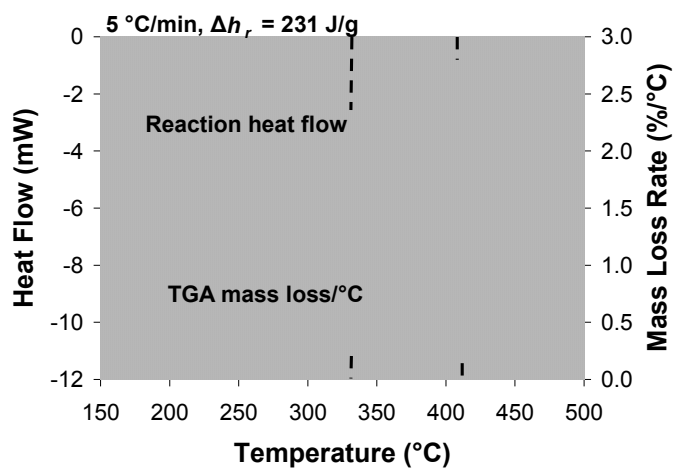

(b)

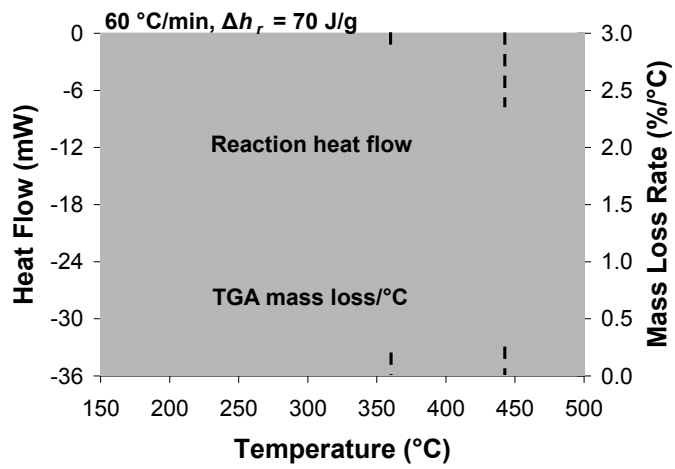

(d) 
Fig. 2. TGA mass loss $/{ }^{\circ} \mathrm{C}$, DSC reaction heat flow and heat of reaction for $\sim 20 \mathrm{mg}$ NFR-SB-31 (F) melts at: (a) $1{ }^{\circ} \mathrm{C} / \mathrm{min}$; (b) $5{ }^{\circ} \mathrm{C} / \mathrm{min}$; (c) $20^{\circ} \mathrm{C} / \mathrm{min}$; (d) $60{ }^{\circ} \mathrm{C} / \mathrm{min}$ heating rates under nitrogen environment.

Integrating the reaction heat flow between $T_{\text {start }}$ and $T_{\text {end }}$ as indicated by the vertical dashed lines, the heat of reaction determined using Eq. 2 for the second reaction is found to reduce greatly from endothermic 357 - $70 \mathrm{~J} / \mathrm{g}$ between 1 and $60{ }^{\circ} \mathrm{C} / \mathrm{min}$. Despite this significant variation, a region of consistency is noted between 5 and $20^{\circ} \mathrm{C} / \mathrm{min}$, where the heat of reaction changes between 231 and $222 \mathrm{~J} / \mathrm{g}$.

The sensitivity towards sample mass is investigated at $5{ }^{\circ} \mathrm{C} / \mathrm{min}$ where Fig. 3 shows the mass loss $/{ }^{\circ} \mathrm{C}$, the reaction heat flow and the calculated heat of reaction for 5, 10, 26 and $46 \mathrm{mg}$ NFR-SB-31 (F) melts. The sample mass of $\sim 50 \mathrm{mg}$ is the maximum limit based on the cup capacity.

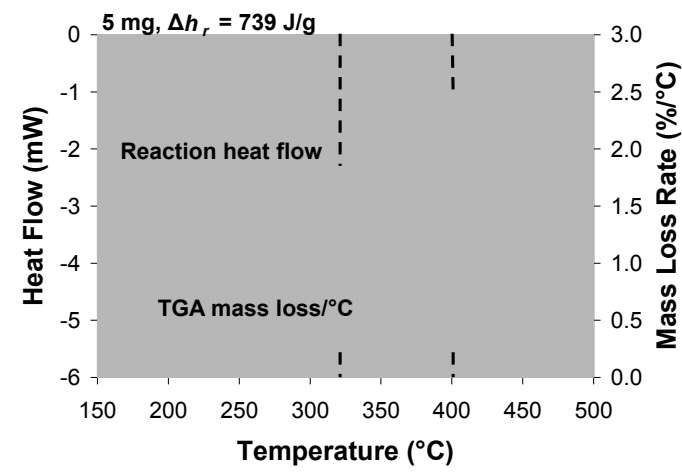

(a)

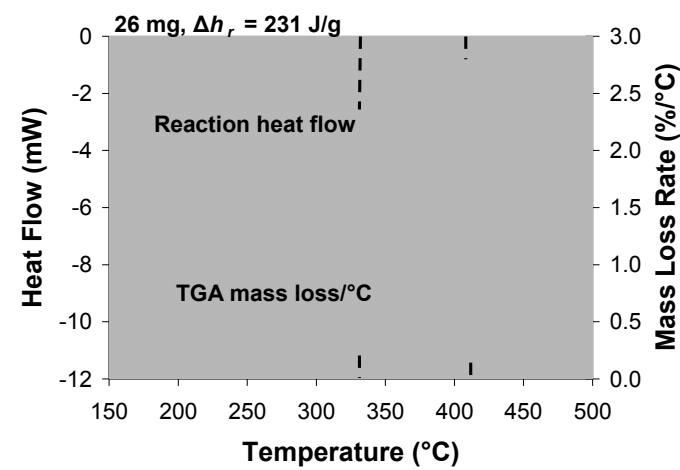

(c)

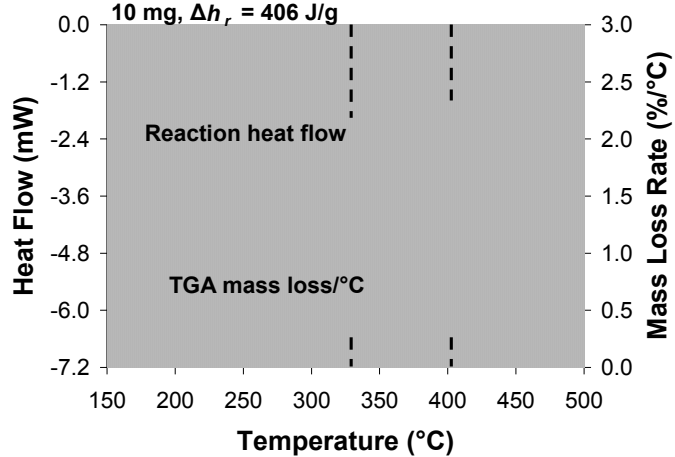

(b)

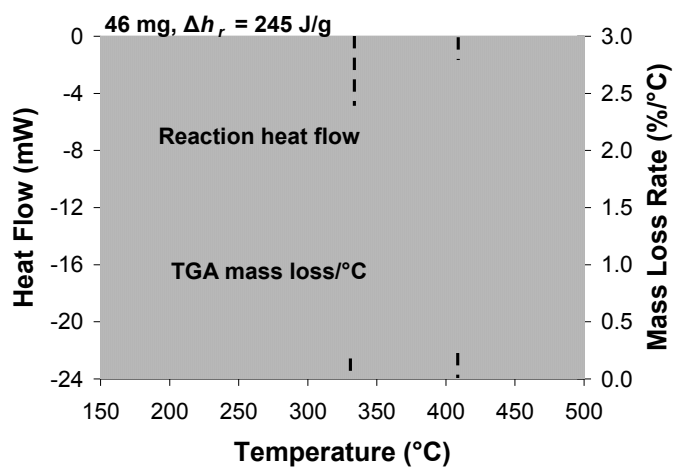

(d)

Fig. 3. TGA mass loss $/{ }^{\circ} \mathrm{C}$, DSC reaction heat flow and heat of reaction for: (a) $5 \mathrm{mg}$; (b) $10 \mathrm{mg}$; (c) $26 \mathrm{mg}$; (d) $46 \mathrm{mg}$ NFR-SB-31 (F) melts at $5{ }^{\circ} \mathrm{C} / \mathrm{min}$ under nitrogen environment.

After integrating the reaction heat flow, the calculated heat of reaction from Eq. 2 is found to be endothermic and its magnitude reduces exponentially when the sample mass increases. At $5 \mathrm{mg}$, the heat of reaction is largest at $739 \mathrm{~J} / \mathrm{g}$ and it diminishes to $406 \mathrm{~J} / \mathrm{g}$ by $10 \mathrm{mg}$. Then it plateaus at 26 and $46 \mathrm{mg}$ with consistent values of 231 and $245 \mathrm{~J} / \mathrm{g}$ respectively.

From the sensitivity analysis, the region of consistent heat of reaction is established which is between the heating rate of 5 and $20{ }^{\circ} \mathrm{C} / \mathrm{min}$ and between the sample mass of $\sim 20$ and $\sim 50 \mathrm{mg}$. Similar heat flow patterns and region of consistency are also noted for the other melt sample, FR-Y-36 (F). From 5 to $20{ }^{\circ} \mathrm{C} / \mathrm{min}$, the consistent values of FR-Y-36 (F) vary between endothermic 203 and $179 \mathrm{~J} / \mathrm{g}$ and from $\sim 20$ to $\sim 50 \mathrm{mg}$, the values vary between endothermic 203 and $212 \mathrm{~J} / \mathrm{g}$. The melts of other polyurethane foams are tested within the region of consistency, at heating rate of $5{ }^{\circ} \mathrm{C} / \mathrm{min}$ and with sample mass of $\sim 20 \mathrm{mg}$. Similar to Fig. 1, all the results collectively show the melt decomposition as a single endothermic reaction. Fig. 4 shows the consistent heat of reaction for all melts tested under nitrogen environment and the values range from $164-295 \mathrm{~J} / \mathrm{g}$. The results show that the melts of FR-Y-36 and FR-LG-38 have a slightly lower 
heat of reaction than the other foams. The heat of reaction between the melts produced under non-flaming and flaming conditions is similar with no distinctive trend. Since NFR-SB-31 (F) and FR-Y-36 (F) melts are tested at multiple heating rates and sample mass, the average of the values from the consistent region is reported in Fig. 4.

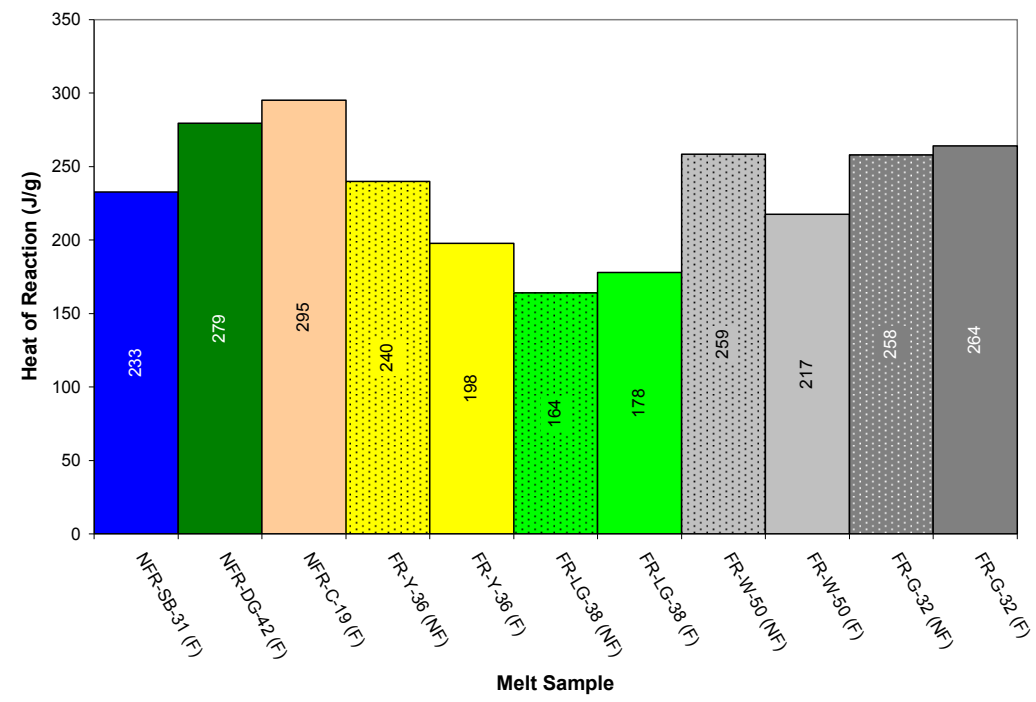

Fig. 4. Consistent heat of reaction for the second reaction, melt decomposition under nitrogen environment.

\section{HEAT OF REACTION FOR DECOMPOSITION OF POLYURETHANE FOAMS (FIRST REACTION)}

The previous section focuses on the heat of reaction for melt decomposition which corresponds to the second reaction in the complete decomposition of polyurethane foam in nitrogen. In this section, the heat of reaction for the first reaction involving the decomposition of foam into melt and gas is analysed. The results of NFR-SB-31 are presented to illustrate the sensitivity towards the heating rate and sample mass. Fig. 5 shows the mass $\operatorname{loss} /{ }^{\circ} \mathrm{C}$, the reaction heat flow and the calculated heat of reaction for $\sim 3 \mathrm{mg}$ NFR-SB-31 at heating rate of $1,5,20$ and $60{ }^{\circ} \mathrm{C} / \mathrm{min}$. The sample decomposes completely over two reactions and this is depicted by the two protuberances in the TGA mass loss $/{ }^{\circ} \mathrm{C}$.

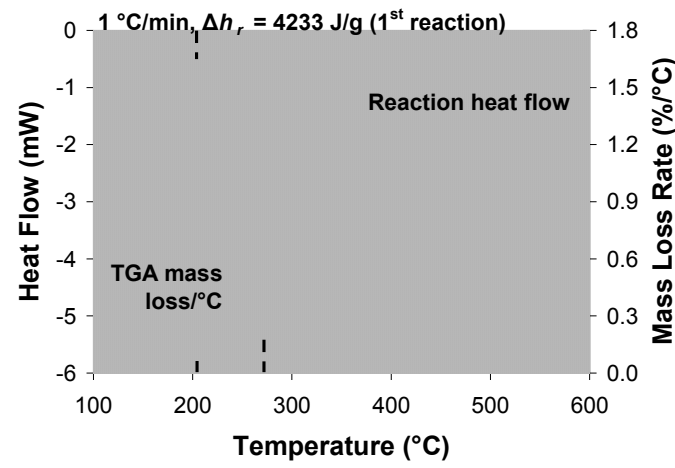

(a)

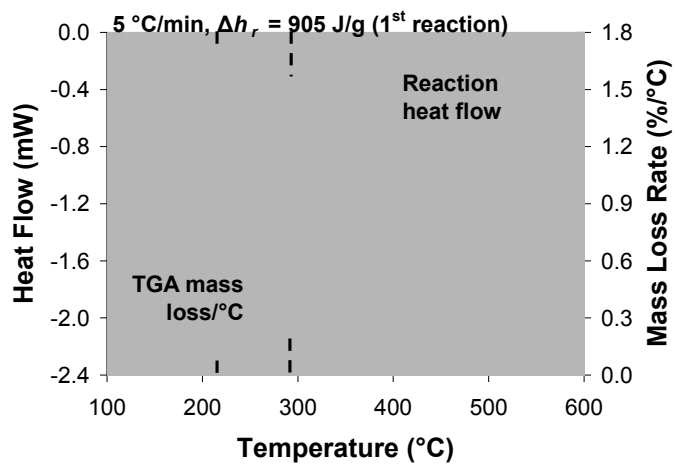

(b) 


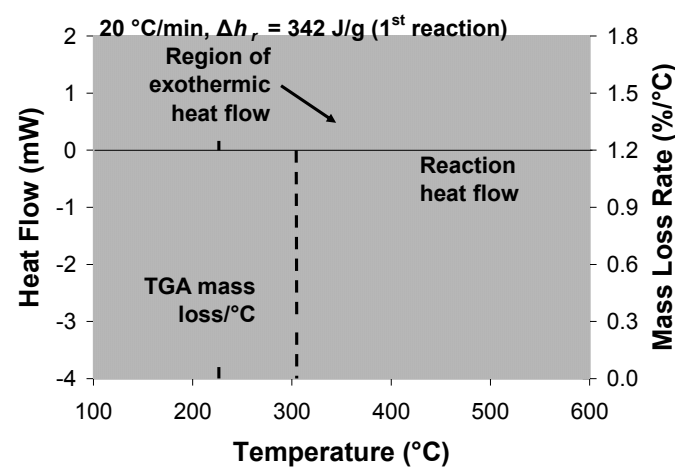

(c)

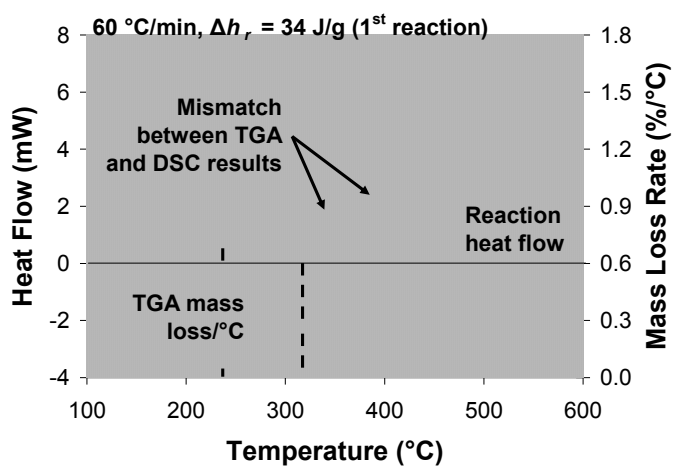

(d)

Fig. 5. TGA mass loss $/{ }^{\circ} \mathrm{C}$, DSC reaction heat flow and heat of reaction for $\sim 3 \mathrm{mg}$ NFR-SB-31 at: (a) $1{ }^{\circ} \mathrm{C} / \mathrm{min}$; (b) $5{ }^{\circ} \mathrm{C} / \mathrm{min}$; (c) $20^{\circ} \mathrm{C} / \mathrm{min}$; (d) $60^{\circ} \mathrm{C} / \mathrm{min}$ heating rates under nitrogen environment.

From Fig. 5, the heat flow resolution is noted to deteriorate as the heating rate increases. At 1 and $5{ }^{\circ} \mathrm{C} / \mathrm{min}$, the two protuberances of the TGA mass loss $/{ }^{\circ} \mathrm{C}$ compare well with the two endothermic regions of the reaction heat flow but at $20^{\circ} \mathrm{C} / \mathrm{min}$, the reaction heat flow shows the presence of an exothermic region in between the first and second reactions and by $60{ }^{\circ} \mathrm{C} / \mathrm{min}$, the TGA and DSC results has become incomparable as the heat flow resolution deteriorates severely. At the different heating rates in Fig. 5, the heat of reaction for the first reaction is obtained from Eq. 2 which involves integrating the reaction heat flow over the first reaction and then dividing by the mass loss over the same interval. The results show a significant reduction in magnitude when the heating rate increases. While discrediting the results at 20 and $60{ }^{\circ} \mathrm{C} / \mathrm{min}$ on the basis of deteriorated resolution, the endothermic value still changes greatly from $4233-$ $905 \mathrm{~J} / \mathrm{g}$ between 1 and $5^{\circ} \mathrm{C} / \mathrm{min}$.

The sensitivity of sample mass is investigated at $5{ }^{\circ} \mathrm{C} / \mathrm{min}$ where Fig. 6 shows the mass $\operatorname{loss} /{ }^{\circ} \mathrm{C}$, the reaction heat flow and the calculated heat of reaction for 3 and $10 \mathrm{mg}$ NFR-SB-31. The sample mass of $\sim 10 \mathrm{mg}$ for foam is the maximum limit of the cup capacity. The TGA mass loss $/{ }^{\circ} \mathrm{C}$ shows the foam sample decomposes via two reactions and at $5{ }^{\circ} \mathrm{C} / \mathrm{min}$, the heat flow obtained has distinguishable resolution. Integrating the heat flow and dividing by the mass loss, the heat of reaction for the first reaction remains similar for the 3 and $10 \mathrm{mg}$ sample sizes, varying between endothermic 905 and $876 \mathrm{~J} / \mathrm{g}$.

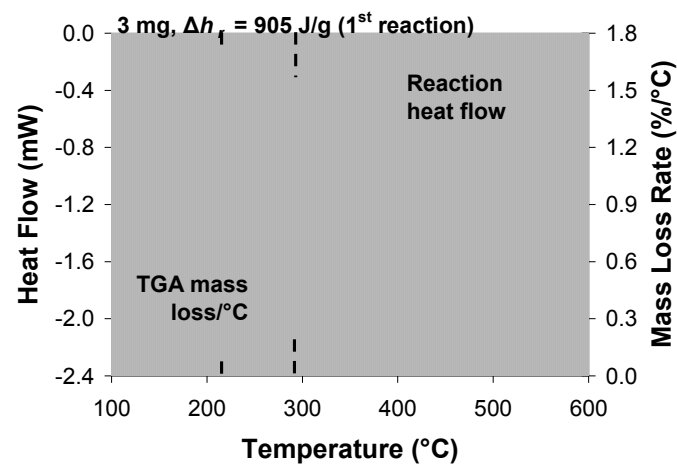

(a)

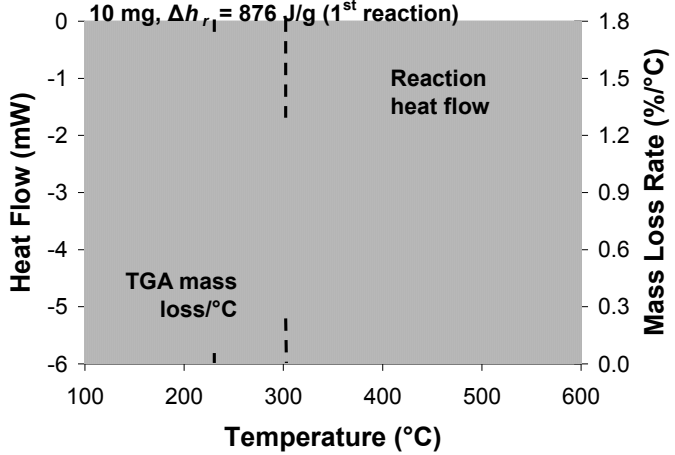

(b)

Fig. 6. TGA mass loss $/{ }^{\circ} \mathrm{C}$, DSC reaction heat flow and heat of reaction for: (a) $3 \mathrm{mg}$; (b) $10 \mathrm{mg}$ NFR-SB-3 1 at $5{ }^{\circ} \mathrm{C} / \mathrm{min}$ under nitrogen environment.

All the other foams are tested at the same sets of experimental conditions, $\sim 3 \mathrm{mg}$ sample at $1,5,20$ and $60{ }^{\circ} \mathrm{C} / \mathrm{min}$ and $\sim 10 \mathrm{mg}$ sample at $5{ }^{\circ} \mathrm{C} / \mathrm{min}$. The $\sim 10 \mathrm{mg}$ sample is not tested as extensively as the $\sim 3 \mathrm{mg}$ sample because fully filled sample cup often contaminates the equipment which affects the heat flow measurements. The changes in the heat of reaction for the other foams are noted to be similar to 
NFR-SB-31. For foam sample, the maximum mass tested is only $\sim 10 \mathrm{mg}$ and this is outside the region of consistency previously determined for the melt sample which requires at least $20 \mathrm{mg}$. The heat of reaction for the second reaction after the foam decomposition is also available and has been presented in [3] but given the current foam sample size, the results are considered less reliable. Different to the melt sample, the region of consistent heat of reaction is not found for the foam sample so among the heating rates tested, the results from $5{ }^{\circ} \mathrm{C} / \mathrm{min}$ are recommended. The basis of the recommendation is that the heat flow resolution and accuracy appear least affected and the magnitude of the heat of reaction for the second reaction is closest to that of the melt sample. The repeatability of reaction heat flow has been investigated for the foam samples of NFR-SB-31 and FR-Y-36 [3]. Repeatable reaction heat flow has been obtained from the three different replicates of each foam.

Fig. 7 shows the recommended heat of reaction for the first reaction under nitrogen environment which ranges between endothermic 610 and $1023 \mathrm{~J} / \mathrm{g}$ for the different polyurethane foams tested. The reported values are the average determined from the heat of reaction for $\sim 3$ and $\sim 10 \mathrm{mg}$ samples at $5{ }^{\circ} \mathrm{C} / \mathrm{min}$.

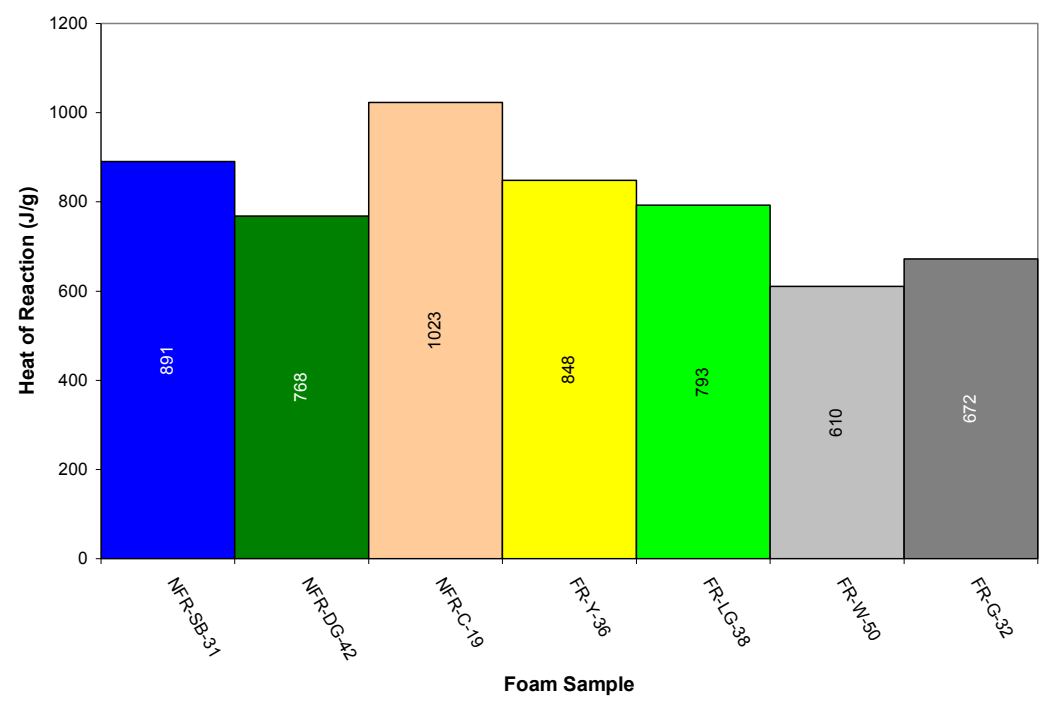

Fig. 7. Recommended heat of reaction for the first reaction, foam decomposition under nitrogen environment.

\section{FACTORS AFFECTING HEAT OF REACTION FROM NITROGEN ENVIRONMENT}

First and foremost, the heat of reaction is influenced by the approach used to obtain the reaction heat flow from the original DSC heat flow. The original heat flow curve contains a few baseline artefacts such as baseline offset, baseline curvature and thermal lag. Fig. 8(a) compares the original and reaction heat flow curves of $26 \mathrm{mg}$ NFR-SB-31 (F) melt at $5{ }^{\circ} \mathrm{C} / \mathrm{min}$ and shows the presence of baseline offset and curvature. Fig. 8(b) shows the results for $22 \mathrm{mg}$ NFR-SB-31 (F) melt at $60^{\circ} \mathrm{C} / \mathrm{min}$ and shows the presence of thermal lag whereby the reaction heat flow curve is shifted by $16{ }^{\circ} \mathrm{C}$ based on the peak in TGA mass loss $/{ }^{\circ} \mathrm{C}$. 


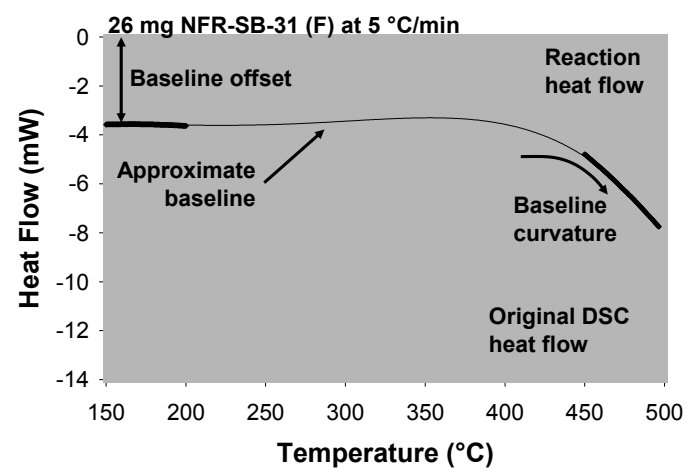

(a)

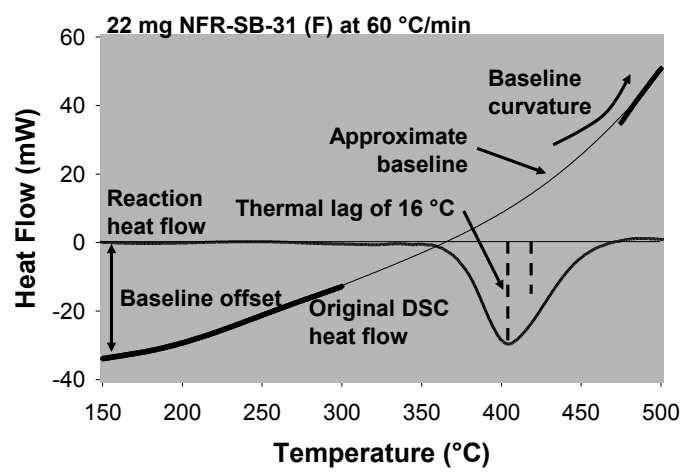

(b)

Fig. 8.: (a) Baseline offset and curvature; (b) thermal lag between original and reaction heat flow curves of NFR-SB-31 (F) melts.

The reaction heat flow is produced from the original heat flow by crudely compensating the baseline offset, baseline curvature and thermal lag via user defined approximate baseline as seen in Fig. 8(a) and (b). A similar baseline correction approach has also been adopted by Valencia [9]. Using Fig. 8(a) as example, the approximate baseline is developed based on the trend of heat flow observed over the non-decomposition regions. From the TGA mass loss $/{ }^{\circ} \mathrm{C}$ which is depicted separately in Fig. 1, the non-decomposition regions are identified as $100-200{ }^{\circ} \mathrm{C}$ and $450-500{ }^{\circ} \mathrm{C}$. The approximate baseline is a polynomial function where the function's degree is user defined. Based on the function's degree and the non-decomposition regions selected, the function's coefficients are solved to produce the optimum correlation. The choice of degree is decided from the R-squared value of the correlation and the expected shape of the baseline. The resulting baseline is indicated in Fig. 8(a) and subtracting from the original curve, the reaction heat flow without offset or curvature is obtained.

Besides the application of baseline correction which is subjective to the user's interpretation, the uncertainties in the heat of reaction are also caused by the physical aspect of the sample, the experimental aspect of the DSC experiment and the chemical aspect of the material decomposition. From Fig. 5, the extreme changes noted in the heat of reaction obtained for the foam sample are related to the sample's porous nature. The thermal contact between the sample and the bottom of the alumina cup is crucial to the accuracy of the heat flow measurements. According to Eq. 1, the heat flow is determined from the temperature difference measured by the thermocouples located underneath the sample and reference cups. The porous structure of the sample means that there are inherent voids between the foam fragments and these fragments also do not form a good thermal contact with the cup. Thus during heating, a localised convective heat flow is believed to develop within these gaps and the impact of this varies with different heating rates which affects the temperature difference measured. The foam sample is prepared by shredding a larger block of foam into smaller fragments and when packed into the cup, the prepared sample becomes more condensed than the original foam. The poor thermal contact and the variation in the density of the prepared sample become the sources of uncertainty in the experiments.

As a result, the heat flow measurements of the foam samples are considered less reliable when compared to the melt samples which have better thermal contact and more consistent density. This is illustrated through a comparison between the calculated and measured baseline offsets. The calculated offset, $(d q / d t)_{\text {off }}$ is determined through Eq. 3 [16] which depends on the sample mass, $m_{\text {sam }}$, the specific heat of the sample, $c_{p}$ and the heating rate of the experiment, $d T / d t$.

$$
\left(\frac{d q}{d t}\right)_{o f f}=m_{s a m} c_{p} \frac{d T}{d t}
$$

In Fig. 9, the calculated baseline offset is plotted against the experimentally measured offset at $100{ }^{\circ} \mathrm{C}$, a temperature prior to any significant decomposition. 


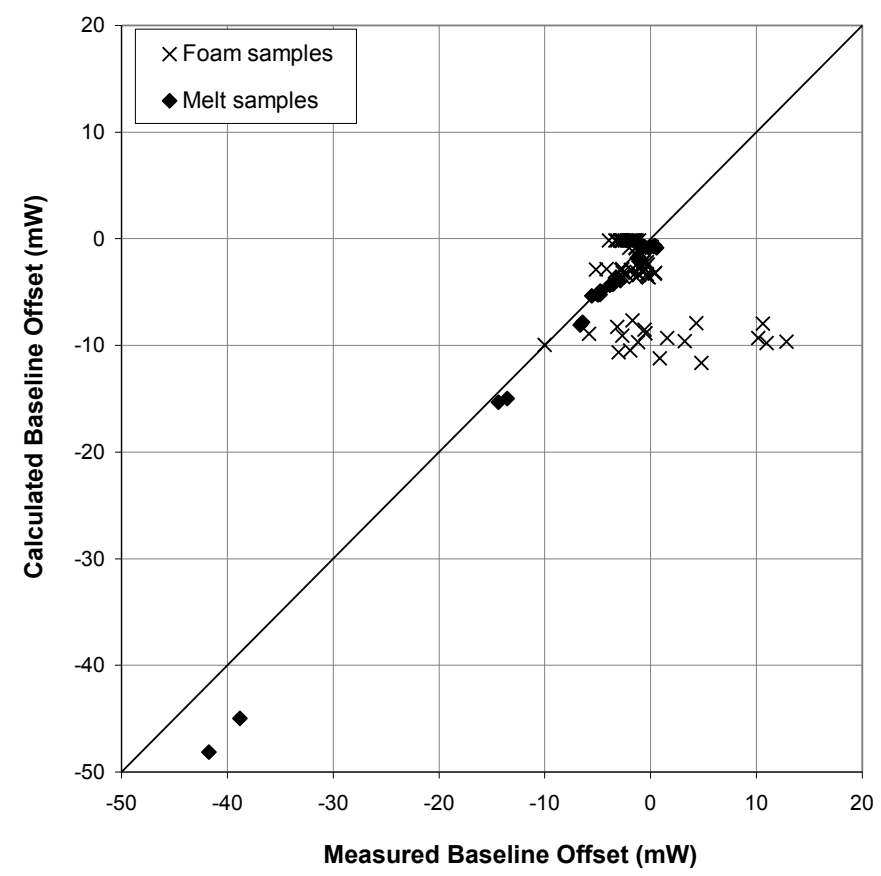

Fig. 9. Calculated baseline offset versus measured baseline offset at $100{ }^{\circ} \mathrm{C}$ for foam and melt samples in SDT experiments.

The results show that in the case of foam samples, the calculated values do not correlate well with the measured values. While the calculated offset is related to sample mass and heating rate as represented by Eq. 3, the measured offset of foam sample does not change in accordance with this relationship. This is caused by the poor thermal contact and also by the poor representation of the sample heat capacity in Eq. 3 which uses the original heat capacity of the foam where in fact, the prepared sample has become more condensed. In the case of the melt samples, a clear linear correlation is established due to the improved thermal contact and the accurate representation of the sample heat capacity. The measured offset of the melt sample is found to increase in magnitude with the increase in sample mass and heating rate, in accordance with the relationship described by Eq. 3 .

While the trend of the baseline offset relates to the physical condition of the sample, the changes in the gradient of the heat flow curvature relates to the experimental variables such as the instrumental effect and the use of lid with the alumina cups. Rath et al. [8] show in their study on woods that the curvature is caused by the additional radiation heat flow between the sample and the furnace which is developed from the difference in emissivity between the sample and reference. Their study demonstrates that when lid is used, the emissivity between the sample and reference remains identical and the curvature is reduced. As lid is not used in this research, the heat flow measurements show curvature which changes in gradient, from negative to positive as the heating rate increases. This change in gradient is depicted by the original heat flow curves in Fig. 8(a) and (b) whereby the heating rate increases from 5 to $60{ }^{\circ} \mathrm{C} / \mathrm{min}$. For future research, a better estimate of this additional radiation heat flow can be made by measuring the heat flow of sample cup containing the char residue of polyurethane foam or melt from a previous experiment.

Besides the offset and curvature, the heat flow measurements also experience thermal lag and reduced resolution. Since the necessary temperature calibration has been performed to correct for the experimental temperature lag, its continuing presence at $60{ }^{\circ} \mathrm{C} / \mathrm{min}$ as seen in Fig. 8(b) requires further explanations. One explanation for the continuous presence of thermal lag is the difference in the heat capacity of the sample and the metal standard used for calibration, zinc. Comparing the specific heat of foams and melts with zinc, the formers range from $2000-3000 \mathrm{~J} / \mathrm{kgK}$ [3] while the latter is $389 \mathrm{~J} / \mathrm{kgK}$ [17]. This shows the specific heat of foams and melts are 5 to 8 times that of zinc. Also, the melting and vaporisation of a pure material such as zinc often take place over a narrow and specific temperature interval. Although represented by two reactions, polyurethane foam consists of many complex chemicals and the decomposition occurs over 
wider range due to the different reacting temperatures. Hence, the decomposition of a complex material becomes more susceptible to the changes in experimental conditions such as heating rate. Another explanation is the lower accuracy of the single point temperature calibration adopted for this research thus in the future, multiple points calibration should be performed within the temperature range of interest [15]. Regarding reduced resolution, the deterioration is caused by the collapse of porous foam structure into a thin layer of melt which introduces experimental noise into the heat flow signal. High heating rate severely deteriorates the resolution of foam sample experiment as seen in Fig. 5 because at $60{ }^{\circ} \mathrm{C} / \mathrm{min}$, the foam sample decomposes rapidly into melt over 10 minutes while at $1{ }^{\circ} \mathrm{C} / \mathrm{min}$, the same process occurs slowly over 8 hours. In contrast, the melt samples have identifiable resolution at all the heating rates tested as they do not experience as much disturbances as the foam samples during decomposition.

The poorly correlated baseline offset of foam samples is explained by the sample porosity which is the physical issue. The experimental issues such as instrumental effects and presence of lid explain the changes to the gradient of the heat flow curvature. However, these do not explicitly explain the significant changes in the heat of reaction with respect to heating rate and sample mass, especially in the case of melt sample where it is not porous. Therefore, the changes in heat of reaction are believed to be related to the decomposition chemistry of material. Through detailed gas chromatography and mass spectrometry (GC/MS) techniques, there are often more than twenty different complex chemicals detected following the decomposition of polyurethane. Bilbao et al. [18] described the decomposition of polyurethane as involving multiple competitive micro reactions which produce several decomposition products. Some of the products are intermediate chemicals which are able to further dissociate into a number of atomic, molecular and free radical species [19]. The micro reactions and secondary dissociations either absorb or release energy to proceed which causes the changes in enthalpy and affects the heat flow measured [20]. These processes are also affected by the changes in heating rate which alter the reaction rate and the composition of the decomposition products. This sensitive nature of polyurethane foam decomposition is considered as a likely explanation for the trend seen in its heat of reaction.

Zhang et al. [21] measured the yield of polyurethane decomposition products with temperature. They found a temperature region between approximately 400 to $550{ }^{\circ} \mathrm{C}$ where the yields are relatively constant but outside this temperature region, the product yields varied. Although the decomposition temperature does not translate directly into heating rate, the constant product yield with changing temperature indicates the possibility of a similar trend between the product yield and heating rate. This should be investigated in the future and if such trend exists, then the changes in the yield and composition of decomposition products with heating rate will hopefully justify the region of consistency found and explain the changes noted in the heat of reaction. This hypothesis is also supported by the findings from Rath et al. [8] where a linear relationship is found between the final char yield of woods and their heat of reaction. While char yield is not a suitable variable for the case of foam due to its low value, the yields of various gaseous products are of interest. These yields can be determined through the methodology demonstrated by Valencia et al. [2].

According to the manufacturer's information, the raw ingredients in NFR and FR foams are similar with the exception that fire retardant additives such as melamine and halophosphate are presence in the FR foams. The effects these fire retardant additives have on the heat of reaction are not obvious. However, in Fig. 4, the melts of FR-Y-36 and FR-LG-38 shows lower endothermic value than the others and this is believed to be a result of the exothermic char formation from the breakdown of melamine remnants in the melts. The mechanism of melamine as fire retardant additive was studied by Price et al. [22] and Denecker et al. [23] but their findings were inconclusive. The former reported an exothermic process as a result of char formation by melamine while the latter reported an endothermic process as a result of melamine sublimation. This is believed to be dependent on the melamine concentration which can vary for different foam formulations. As melamine experiences both endothermic sublimation and exothermic char formation, its varying concentration affects the competition between both reactions and has a direct impact on the heat of reaction.

\section{CONCLUSIONS}

In this research, SDT is used to determine the heat of reaction from the decomposition of polyurethane foams and their melts under nitrogen environment. The foam samples experience two separate pyrolysis reactions while the melt samples which have already undergone the first reaction experience the second reaction only. From the DSC results, the nature of the decomposition for both the first and second reactions 
is endothermic. The heat of reaction for the first reaction is obtained from the decomposition of polyurethane foam samples while the heat of reaction for the second reaction is obtained from the decomposition of the melt samples. The heat of reaction for the second reaction is also available from the decomposition of the foam sample but these values are not recommended because of the inherent reduced heat flow accuracy for a foam sample.

Despite the large variation in the heat of reaction obtained with respect to the changes in heating rate and sample mass tested, a consistent region is established for the second reaction involving the decomposition of melt. This region includes heating rate from 5 to $20{ }^{\circ} \mathrm{C} / \mathrm{min}$ and sample mass from $\sim 20$ to $\sim 50 \mathrm{mg}$. No consistent region is determined in the case of the first reaction which involves the decomposition of foam sample. This is caused by the porous nature of the sample which creates a poor thermal contact with the bottom of the cup and this produces uncertainties in the heat flow measurements. In addition, the inconsistency of the heat of reaction may also be caused by the changes in the yield and composition of the decomposition products. Through GC/MS techniques, several studies in the literature have revealed that the yield and composition of the products from polyurethane decomposition varies with respect to temperature. The consistent heat of reaction for the second reaction ranges from endothermic $164-295 \mathrm{~J} / \mathrm{g}$ while the recommended values of the first reaction ranges from endothermic $610-1023 \mathrm{~J} / \mathrm{g}$. The variations in the heat of reaction for different NFR and FR foams and also non-flaming and flaming melts are considered to be within the experimental uncertainties. The range of heat of reaction reported for the first and second reactions are similar to the values reported by Valencia [9] which are endothermic 1009 and $331 \mathrm{~J} / \mathrm{g}$ respectively.

\section{REFERENCES}

[1] Rein, G., Launtenberger, C., Fernandez-Pello, A. C., Torero, J. L., and Urban, D. L., (2006) Application of Genetic Algorithms and Thermogravimetry to Determine the Kinetics of Polyurethane Foam in Smoldering Combustion, Combustion and Flame 146(1-2): 95-108, http://dx.doi.org/10.1016/j.combustflame.2006.04.013

[2] Valencia, L. B., Rogaume, T., and Guillaume, E., "New Method for Simulating the Kinetic of Toxic Gases Production of Upholstered Furniture Fire", Fire and Materials -- Proceedings of the Eleventh International Conference, Interscience Communications Limited, 2009, pp. 685-695.

[3] Pau, D. S. W., “A Comparative Study on Combustion Behaviours of Polyurethane Foams with Numerical Simulations Using Pyrolysis Models", PhD's thesis, University of Canterbury, Christchurch, 2013.

[4] Prasad, K., Kramer, R., Marsh, N., Nyden, M., Ohlemiller, T., and Zammarano, M., "Numerical Simulation of Fire Spread on Polyurethane Foam Slabs", Fire and Materials -- Proceedings of the Eleventh International Conference, Interscience Communications Limited, 2009, pp. 697-708.

[5] Chang, R., Chemistry, McGraw-Hill, New York, 2002, p. 205-244.

[6] McGrattan, K., Baum, H., Rehm, R., Mell, W., McDermott, R., Hostikka, S., and Floyd, J., "Fire Dynamics Simulator (Version 5) Technical Reference Guide, Volume 1: Mathematical Model, FDS Version 5.5, SVN Repository Revision: 6909”, National Institute of Standards and Technology Special Publication 1018-5, Gaithersburg, MD, 2010.

[7] Lautenberger, C., "Gpyro - A Generalized Pyrolysis Model for Combustible Solids, Technical Reference, Version 0.700", Department of Mechanical Engineering, University of California, Berkeley, CA, 2009.

[8] Rath, J., Wolfinger, M. G., Steiner, G., Krammer, G., Barontini, F., and Cozzani, V., (2003) Heat of Wood Pyrolysis, Fuel 82(1): 81-91, http://dx.doi.org/10.1016/S0016-2361(02)00138-2

[9] Valencia, L. B., "Experimental and Numerical Investigation of the Thermal Decomposition of Materials at Three Scales: Application to Polyether Polyurethane Foam Used in Upholstered Furniture", PhD's thesis, University of Edinburgh, Edinburgh, 2009. 
[10] Stoliarov, S. I., and Walters, R. N., (2008) Determination of the Heats of Gasification of Polymers Using Differential Scanning Calorimetry, Polymer Degradation and Stability 93(2): 422-427, http://dx.doi.org/10.1016/j.polymdegradstab.2007.11.022

[11] Matala, A., Hostikka, S., and Mangs, J., "Estimation of Pyrolysis Model Parameters for Solid Materials Using Thermogravimetric Data", Fire Safety Science -- Proceedings of the Ninth International Symposium, International Association for Fire Safety Science, 2009, pp. 1213-1223.

[12] Matala, A., "Estimation of Solid Phase Reaction Parameters for Fire Simulation”, Master's thesis, Helsinki University of Technology, Espoo, 2008.

[13] Peterson, J. D., Vyazovkin, S., and Wight, C. A., (1999) Stabilizing Effect of Oxygen on Thermal Degradation of Poly(methylmethacrylate), Macromolecular Rapid Communications 20(9): 480483, http://dx.doi.org/10.1002/(SICI)1521-3927(19990901)20:9<480::AID-MARC480>3.0.CO;2$\underline{7}$

[14] Kalsi, H. S., Electronic Instrumentation, Tata McGraw-Hill, New Delhi, 2010, p. 25-63.

[15] Q Series ${ }^{\mathrm{TM}}$ Getting Started Guide, SDT Simultaneous DSC-TGA, TA Instruments, New Castle, DE, 2007.

[16] Cassel, R. B., "How Tzero ${ }^{\mathrm{TM}}$ Technology Improves DSC Performance, Part III: The Measurement of Specific Heat Capacity”, TA Instruments, New Castle, DE, 2001.

[17] Incropera, F. P., and Dewitt, D. P., Fundamentals of Heat and Mass Transfer, John Wiley \& Sons Inc., Hoboken, 2002, p. 903-932.

[18] Bilbao, R., Mastral, J. F., Ceamanos, J., and Aldea, M. E., (1996) Kinetics of the Thermal Decomposition of Polyurethane Foams in Nitrogen and Air Atmospheres, Journal of Analytical and Applied Pyrolysis 37(1): 69-82, http://dx.doi.org/10.1016/0165-2370(96)00936-9

[19] Drysdale, D., An Introduction to Fire Dynamics, John Wiley \& Sons, West Sussex, 2011, p. 1-34.

[20] Cassel, R. B., "How Tzero ${ }^{\mathrm{TM}}$ Technology Improves DSC Performance, Part IV: MDSC ( Enhancement”, TA Instruments, New Castle, DE, 2001.

[21] Zhang, Y., Xia, Z., Huang, H., and Chen, H., (2009) Thermal Degradation of Polyurethane Based on IPDI, Journal of Analytical and Applied Pyrolysis 84(1): 89-94, http://dx.doi.org/10.1016/j.jaap.2008.11.008

[22] Price, D., Liu, Y., Milnes, G. J., Hull, R., Kandola, B. K., and Horrocks, A. R., (2002) An Investigation into the Mechanism of Flame Retardancy and Smoke Suppression by Melamine in Flexible Polyurethane Foam, Fire and Materials 26(4-5): 201-206, http://dx.doi.org/10.1002/fam.810

[23] Denecker, C., Liggat, J. J., and Snape, C. E., (2006) Relationship Between the Thermal Degradation Chemistry and Flammability of Commercial Flexible Polyurethane Foams, Journal of Applied Polymer Science 100(4): 3024-3033, http://dx.doi.org/10.1002/app.23701 